\title{
ESTRUTURADOS DE CAJÁ-MANGA (Spondias dulcis) COM DIFERENTES HIDROCOLOIDES
}

Laís Ferreira ${ }^{1}$, Luciana Santos Rodrigues Costa Pinto ${ }^{2}$

${ }^{1}$ Graduanda em Engenharia Agronômica, Instituto Federal do Triângulo Mineiro -

Campus Uberlândia, Minas Gerais, Brasil (lais.ferreira.agro@gmail.com)

2 Professora Doutora do Instituto Federal do Triângulo Mineiro - Campus Uberlândia, Minas Gerais, Brasil

Recebido em: 08/04/2017 - Aprovado em: 10/06/2017 - Publicado em: 20/06/2017 DOl: 10.18677/EnciBio_2017A49

\begin{abstract}
RESUMO
A fruta estruturada ou gel de fruta é uma alternativa de oferecer ao consumidor um produto com maior quantidade de polpa de fruta, acrescentando maior teor nutritivo com a adição de hidrocoloides e coadjuvantes tecnológicos. O objetivo deste trabalho foi elaborar e caracterizar diferentes formulações de estruturados de polpa de frutos de cajá-manga empregando-se três hidrocoloides. Os hidrocoloides utilizados foram a pectina, gelatina e alginato de sódio. Além dos hidrocoloides foram incluídos nas formulações a sacarose e o glicerol como coadjuvantes tecnológicos que contribuíram na estruturação do produto elaborado. Foram testadas quatro formulações (T1, T2, T3 e T4), alternando-se os hidrocoloides adicionados. A polpa de cajá-manga e os estruturados obtidos da fruta foram caracterizados quanto ao $\mathrm{pH}$, sólidos solúveis, umidade, cinzas, proteínas, lipídios e o valor energético total. Adotou-se um delineamento experimental inteiramente casualizado, com três repetições avaliadas em duplicata para as análises físicoquímicas. Os resultados mostraram que a formulação 3 (T3: gelatina + pectina) apresentou melhores resultados para os parâmetros nutricionais avaliados e a formulação 2 (T2: pectina + alginato) apresentou maior teor de umidade e menores teores de proteínas, carboidratos, $\mathrm{pH}$, sólidos solúveis e valor calórico total quando comparado com as demais formulações. Pode-se concluir que a metodologia utilizada possibilitou o desenvolvimento de estruturados de polpa de cajá-manga e que a gelatina foi o hidrocoloide que mais afetou o teor de proteínas e a firmeza dos produtos alimentícios elaborados.
\end{abstract}

PALAVRAS-CHAVES: Alginato de Sódio. Cerrado. Gelatina. Pectina.

\section{AMBARELLA (Spondias dulcis) STRUCTURED WITH DIFFERENT HYDROCOLOIDS}

\begin{abstract}
The structured fruit or fruit gel is an alternative to offer the consumer a product with greater amount of fruit pulp, adding greater nutritive content with the addition of hydrocolloids and technological aids. The aim of this work was to elaborate and characterize different formulations of structured ambarella pulp using three hydrocolloids. The hydrocolloids used were pectin, gelatin and sodium alginate. In addition to the hydrocolloids sucrose and glycerol were included in the formulations
\end{abstract}


as technological aids that contributed to the structuring of the elaborated product. Four formulations were tested (T1, T2, T3 and T4) alternating the added hydrocolloids. The ambarella pulp and the structured obtained from the fruit were characterized as to $\mathrm{pH}$, soluble solids, moisture, ashes, proteins, lipids and the total energetic value. It was used a completely randomized experimental design, with three replicates evaluated in duplicate for the physicochemical analyzes. The results showed that formulation 3 (T3: gelatin + pectin) presented better results for the evaluated nutritional parameters and the formulation 2 (pectin + sodium alginate) presented higher moisture content and lower levels of proteins, carbohydrates, $\mathrm{pH}$, soluble solids and total caloric value when compared to the other formulations. It can be concluded that the methodology used allowed the development of ambarella pulp structured and gelatine was the hydrocolloid that most affected the protein content and firmness of processed foods.

KEYWORDS: Sodium alginate. Cerrado. Gelatine. Pectin

\section{INTRODUÇÃO}

O Cerrado constitui um imenso patrimônio de recursos naturais renováveis, com ênfase para as espécies frutíferas exóticas detentoras de características sensoriais peculiares e intensas. Estas características únicas conferem aos frutos do cerrado um potencial de exploração nacional e internacional, despertando o interesse dos consumidores e contribuindo com a busca das indústrias por inovações que proporcionem um desenvolvimento competitivo (MORZELLE et al., 2015). Segundo RUFINO et al. (2010) o Cerrado carece de estudos que ampliem o conhecimento de suas espécies e podem ajudar na preservação do Bioma em questão, tanto na disponibilização de alternativas de renda pela utilização dos recursos naturais locais, através do manejo econômico sustentável, quanto na demonstração dos benefícios nutricionais desses produtos agrícolas.

No Brasil, frutos exóticos e não tradicionais, como os do cerrado, apesar de serem apreciados por suas propriedades nutricionais e sensoriais como aroma e sabor, apresentam uma vida útil pós-colheita relativamente curta, o que tem dificultado a comercialização e requerem técnicas especiais para conservação e comercialização, inclusive para agregar-Ihes valor (RUFINO et al. 2010). Dentre as técnicas de processamento e industrialização de frutos, a estruturação de polpa de frutas conhecida como fruta estruturada ou "gel de frutas" representa uma inovação com resultados bastante promissores (CARVALHO et al., 2015).

A cajá-manga (Spondias dulcis) pertence à família Anacadiaceae, a qual pertencem outras espécies do gênero Spondias, tais como: o umbu (Spondias tuberosa), a ciriguela (Spondia purpurea), a cajazeira (Spondias mombin) e o umbucajazeira (Spondias sp.) (SILVA et al., 2014). Esta frutífera é originária das Ilhas da Polinésia, mas adaptou-se ao Cerrado brasileiro por possuir características que representam o bioma, sendo então, conhecida popularmente como um fruto do cerrado, do qual originam diversos subprodutos. O fruto apresenta forma elipsoidal do tipo drupa, a polpa é composta por fibras rígidas e espinhosas, sendo considerada suculenta, agridoce e fortemente aromática (SIQUEIRA et al., 2017). Por apresentar na constituição compostos bioativos como antioxidantes, carotenoides e vitaminas, a cajá-manga tem despertado o interesse de pesquisadores, tanto para cultivo quanto para o processamento o que justifica a busca por técnicas que permitam a conservação dos frutos e dos nutrientes e oferta fora do período de safra. 
O desenvolvimento de estruturados de frutos de cerrado como a cajá-manga, é uma alternativa para o aproveitamento do potencial agroindustrial e nutricional desse fruto, pois pode aumentar a vida pós-colheita sem comprometer a qualidade e ainda possibilitam a descoberta e a popularização dos sabores e benefícios à saúde dessa matéria-prima regional. Entretanto, há carência de informações sobre os procedimentos tecnológicos empregados, a correta formulação dos ingredientes usados na elaboração de produtos estruturados e o efeito da secagem na textura dos produtos estruturados (OLIVEIRA et al. 2012).

Diante do exposto e pela importância do sistema produtivo de fruteiras do cerrado o presente trabalho teve por objetivo elaborar, a partir de polpa concentrada de cajá-manga, um estruturado conhecido como "gel de fruta" ou "jujuba" de frutas e avaliar as características físico-químicas da polpa concentrada e dos estruturados obtidos visando tanto o aproveitamento desses frutos quanto torná-los convenientes, de maior valor agregado e atraentes pelas propriedades nutricionais conferidas por essa fruta.

\section{MATERIAL E MÉTODOS}

O processamento dos frutos foi realizado no setor de Processamento de Frutas e Hortaliças do Instituto Federal do Triângulo Mineiro - Campus Uberlândia. Os frutos foram lavados com esponja e água corrente e sanitizados com hipoclorito de sódio por imersão, a 200 ppm de cloro ativo durante 15 minutos. Em seguida, foi realizado o descascamento e o despolpamento manual dos frutos. A polpa obtida foi triturada em processador e peneirada para a retirada das fibras. Teve-se o cuidado de utilizar práticas adequadas de higiene tanto dos manipuladores quanto do ambiente e dos utensílios usados.

Em seguida, foram separadas as unidades experimentais, que consistiram de $400 \mathrm{~g}$ de "purê" de cajá-manga por tratamento. Às unidades experimentais de "purê" foram acrescentados três hidrocoloides: pectina, gelatina e alginato de sódio $\left(\mathrm{NaC}_{6} \mathrm{H}_{7} \mathrm{O}_{6}\right)$. Além dos hidrocoloides foram incluídos nas formulações coadjuvantes tecnológicos que contribuíram na estruturação do produto elaborado, foram eles: sacarose e glicerol. Foram testadas quatro formulações com diferentes combinações de hidrocolóides e coadjuvantes (Tabela 1).

TABELA 1: Especificações das formulações de estruturados de cajámanga testadas.

\begin{tabular}{cccccc}
\hline $\begin{array}{c}\text { Formulações/ } \\
\text { Tratamentos }\end{array}$ & $\begin{array}{c}\text { Alginat } \\
\mathbf{0}(\mathbf{g})\end{array}$ & $\begin{array}{c}\text { Gelatin } \\
\mathbf{a}(\mathbf{g})\end{array}$ & $\begin{array}{c}\text { Pectina } \\
(\mathbf{g})\end{array}$ & $\begin{array}{c}\text { Glicerol } \\
(\mathbf{m l})\end{array}$ & $\begin{array}{c}\text { Sacarose } \\
(\mathbf{g})\end{array}$ \\
\hline $\mathbf{1}$ & 9 & 50 & 15 & 11,5 & 420 \\
$\mathbf{2}$ & 9 & - & 15 & 11,5 & 362 \\
$\mathbf{3}$ & - & 50 & 15 & 11,5 & 403 \\
$\mathbf{4}$ & 9 & 50 & - & 11,5 & 324 \\
\hline
\end{tabular}

A quantidade de sacarose adicionada às formulações foi determinada utilizando-se o cálculo de balanço de massas conforme metodologia proposta por GRIZOTTO et al. (2005) e adaptada por CARVALHO et al. (2015). Calculou-se quantidade de sacarose suficiente para elevar o teor de sólidos solúveis para $50^{\circ}$ Brix utilizando-se a equação $M_{p} \times{ }^{\circ}$ Brix $p+M_{a} \times{ }^{\circ}$ Brix $x_{a}=M_{e} \times{ }^{\circ}$ Brix $x_{e}$, em que: $M_{p}$ : massa da polpa; ${ }^{\circ} B r i x_{p}$ : grau brix da polpa; $\mathrm{M}_{\mathrm{a}}$ : massa do açúcar; ${ }^{\circ} \mathrm{Brix}$ : grau brix do açúcar; $\mathrm{M}_{\mathrm{e}}$ : massa do estruturado; ${ }^{\circ}$ Brix $\mathrm{e}_{\mathrm{e}}$ grau brix do estruturado. 
Cada tratamento, composto por 400 gramas de purê, foi aquecido a $60^{\circ} \mathrm{C}$, em banho-maria digital, onde foram adicionados os componentes da formulação, sendo que, apenas o glicerol foi adicionado antes do aquecimento (Figura 1). A agitação manual ocorreu até a homogeneização do produto. Após a homogeneização, o estruturado foi colocado em placas de Petri esterilizadas para moldagem, e mantidas a $10^{\circ} \mathrm{C}$ por 24 horas para completar a gelificação do produto. Posteriormente, as placas foram levadas para estufa de fluxo de ar à $105^{\circ} \mathrm{C}$ por cinco horas, para secagem do produto. Os estruturados ficaram armazenados em refrigerador até o momento do corte e na sequência foram submetidos às análises físico-químicas.

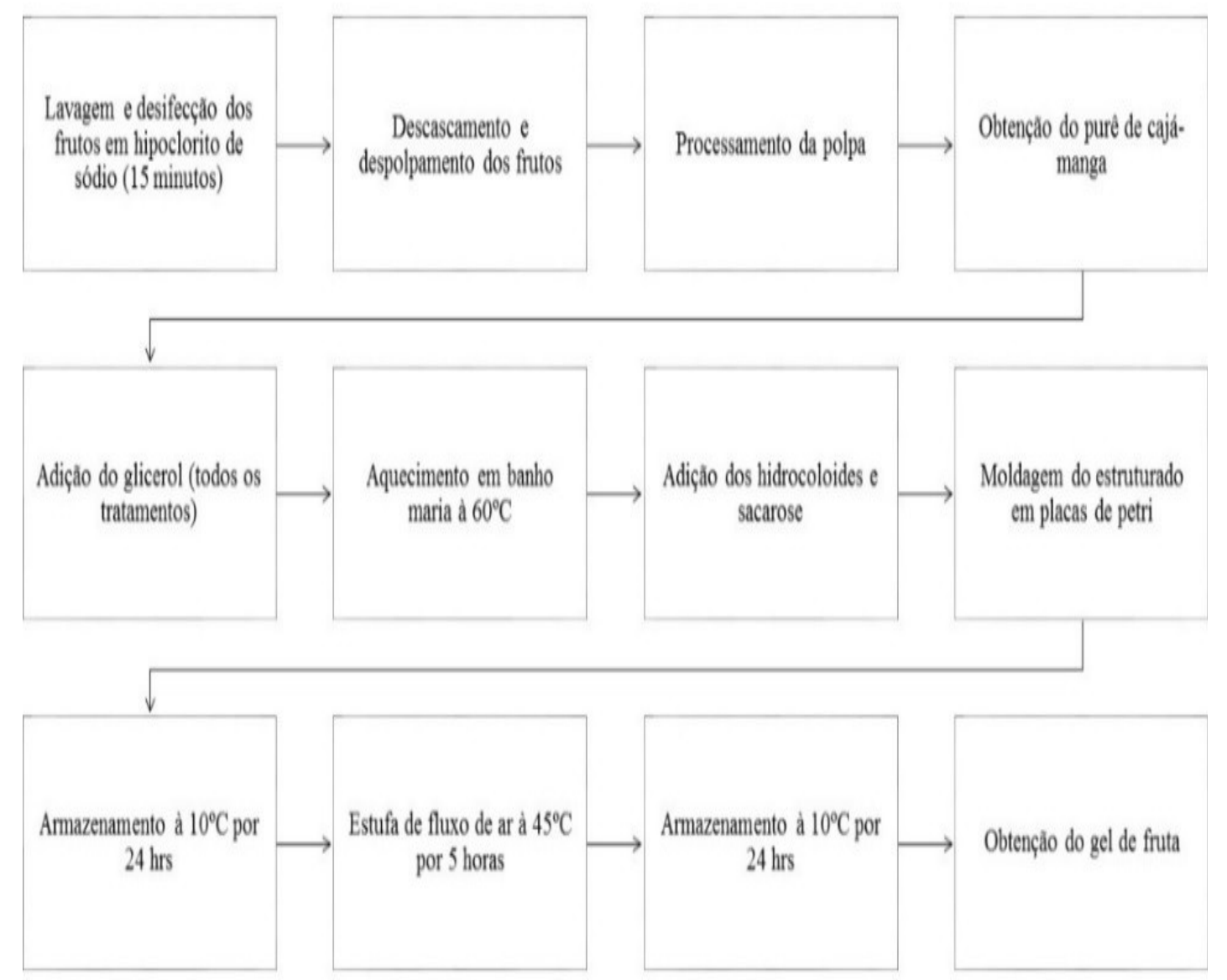

FIGURA 1: Fluxograma de obtenção do estruturado de cajá-manga.

Fonte: Elaborada pelos autores

A polpa de cajá-manga e os estruturados obtidos foram caracterizados quanto ao $\mathrm{pH}$, sólidos solúveis, umidade, cinzas, proteínas, lipídios e teor de carboidratos, que foi calculado pela diferença entre 100 e a soma das porcentagens de água, proteína, lipídeos totais e cinzas. $O$ efeito da secagem sobre os estruturados foi avaliado visualmente, observando-se principalmente a pegajosidade ao toque e a resistência ao corte. Foi adotado um delineamento experimental inteiramente casualizado (DIC), com as quatro formulações repetidas três vezes, que foram analisadas em duplicata para as análises centesimais.

Para a análise de umidade foi utilizado o aparelho Analisador de Umidade por Infravermelho IV 2500. Para isto considerou-se no aparelho a opção de medida de ENCICLOPÉDIA BIOSFERA, Centro Científico Conhecer - Goiânia, v.14 n.25; p.35 
"Doce de Leite", isto por causa da similaridade do estruturado com o produto, então cada amostra foi lida pelo aparelho em 30 minutos, tempo padronizado para o produto "Doce de Leite". O valor energético total dos estruturados foi calculado pelo Fator ou Coeficiente de Atwater utilizando-se a equação VET $=(C \times 4)+(A \times 4)+(B \times 9)$, onde $\mathrm{C}$ : carboidratos, $\mathrm{A}$ : proteína total e $\mathrm{B}$ : extrato etéreo. $\mathrm{O}$ resultado foi expresso em kcal/100g como descrito por BRASIL (2003).

\section{RESULTADOS E DISCUSSÃO}

Foram processadas 52 unidades de cajá-manga, totalizando $4,021 \mathrm{~kg}$ de frutos. O peso da casca foi de $0,726 \mathrm{~kg}$, o peso do purê/polpa de $1,123 \mathrm{~kg}$ e o do caroço de $1,136 \mathrm{~kg}$. O rendimento foi então de 27,92\%. DAMIANI et al. (2011), desenvolvendo um néctar da polpa de cajá-manga acrescido de hortelã, encontraram um rendimento médio de $61,02 \%$ para polpa de cajá-manga com variação de $45,65 \%$ a $69,10 \%$ utilizando frutos amarelo esverdeados. Apesar do menor rendimento obtido nessa proposta comparado com os resultados encontrados pelos autores citados, a diferença ocorreu porque os frutos utilizados na execução do trabalho foram considerados em estágio maduro.

Foram avaliados aspectos nutricionais (proteínas, lipídeos, umidade, carboidratos, cinzas e valor energético total) além do $\mathrm{pH}$ e sólidos solúveis da polpa de cajá-manga e dos estruturados elaborados a partir da polpa. Os resultados da caracterização físico-química da polpa de cajá-manga estão apresentados na Tabela 2.

TABELA 2: Caracterização físico-química da polpa de cajá-manga (Spondias dulcis), em base úmida.

\begin{tabular}{cc}
\hline Característica & Média \\
\hline Umidade (\%) & 71,62 \\
Cinzas (\%) & 0,97 \\
Proteínas (\%) & 3,42 \\
Lipídios (\%) & 0,05 \\
Carboidratos (\%) & 23,85 \\
pH & 2,8 \\
Sólidos Solúveis ( ${ }^{\circ}$ Brix) & 13,75 \\
Valor Energético Total & 109,53 \\
\hline
\end{tabular}

Os resultados obtidos para as análises centesimais da polpa congelada de cajá-manga foram comparados aos da tabela TACO (TABELA BRASILEIRA DE COMPOSIÇÃO DE ALIMENTOS - 2011), e mostraram semelhanças para os quesitos umidade $(86,9 \%)$, proteína $(1,3 \%)$ e cinzas $(0,4 \%)$. Entretanto, não estão disponíveis os dados para a polpa congelada de cajá-manga, apenas para a cajámanga in natura.

Ainda segundo a TACO (2011), a polpa não apresenta lipídios, o que justifica o baixo valor encontrado nas análises do trabalho (0,05\%). Valores semelhantes para lipídios foram encontrados por DAMIANI et al. (2011) que obtiveram valores de $0,04 \%$ para lipídios totais, na polpa de cajá-manga congelada.

$\mathrm{Na}$ análise de $\mathrm{pH}$, o valor obtido foi de 2,8 o qual está semelhante aos resultados encontrados por BUSANELLO (2014), que estudava o desenvolvimento de uma bebida láctea fermentada com cajá-manga, com valor médio de 2,82. DAMIANI et al. (2011) encontraram valor médio de 2,72, enquanto LAGO-VANZELA et al. (2011), desenvolvendo geleia da casca e da polpa de cajá-manga, obtiveram valores de $\mathrm{pH}$ de 3,32, superiores ao encontrado nesta pesquisa. 
O valor de carboidrato $(23,85 \%)$ foi superior aos encontrados por DAMIANI et al. (2011), 15\% e pela TACO (2011), 11,4\%, entretanto, o valor foi inferior ao obtido por BUSANELLO (2014), 37,02\%. Por se tratar de uma inovação tecnológica, ou seja, a elaboração de um produto novo, tanto no quesito formulação, modo de produção e matéria-prima utilizada, não foram encontradas na literatura referências que possam dar suporte a discussão do mesmo com relação a caracterização físicoquímica.

A metodologia utilizada para a elaboração dos estruturados mostrou-se viável para a produção de um produto alimentício macio e mastigável ("gel-de-fruta" ou "jujuba" de fruta). A Figura 2 mostra os estruturados de cajá-manga elaborados, já cortados, antes de serem submetidos as análises físico-químicas. Nas tabelas 3 e 4, estão os resultados estatísticos das análises físico-químicas, comparando as diferentes formulações testadas e a polpa de cajá-manga.

O coeficiente de variação (CV) é uma maneira de expressar a variabilidade dos dados, tirando a influência de ordem de grandeza variável. O CV determina a variabilidade dos dados em relação a média. Logo, quanto menor o coeficiente de variação mais homogêneo é o conjunto de dados. A partir dos dados tabelados considera-se o coeficiente de variação baixo (conjunto de dados razoavelmente homogêneo) quando o valor for menor ou igual a $21 \%$. Analisando-se os coeficientes de variação mostrados na Tabela 3, a exceção da variável lipídio, todos os valores mostraram uma boa precisão experimental considerando-se que os dados analisados foram obtidos em análises laboratoriais e calculados por meio de equação matemática. Segundo a TACO (2011), a polpa de cajá-manga não apresenta lipídios desse modo os baixos valores encontrados podem ter gerado inconsistências de leitura pela metodologia de quantificação utilizada e assim elevado o CV para esse parâmetro.

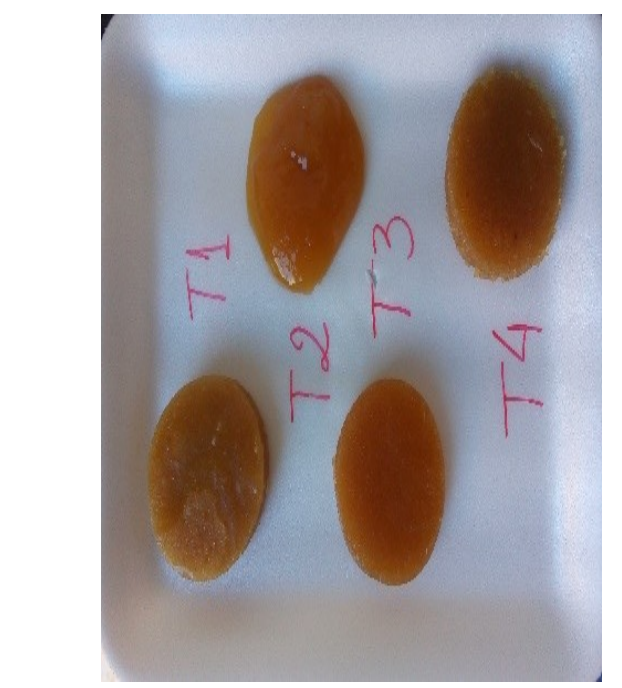

FIGURA 2: Estruturados de cajámanga (T1: alginato, gelatina e pectina; T2: alginato e pectina; T3: gelatina e pectina; T4: alginato e gelatina).

Fonte: Arquivo pessoal dos autores.

TABELA 3: Comparação estatística para as variáveis umidade, cinzas, proteínas, lipídeos e carboidratos para cada formulação do gel de fruta e a polpa de cajá-manga. 


\begin{tabular}{cccccc}
\hline Formulações & $\begin{array}{c}\text { Umidade } \\
(\%)\end{array}$ & $\begin{array}{c}\text { Cinzas } \\
(\%)\end{array}$ & $\begin{array}{c}\text { Proteínas } \\
(\%)\end{array}$ & $\begin{array}{c}\text { Lipídios } \\
(\%)\end{array}$ & $\begin{array}{c}\text { Carboidratos } \\
(\%)\end{array}$ \\
\hline Polpa & $71,62 \mathrm{a}$ & $1,06 \mathrm{a}$ & $3,42 \mathrm{~cd}$ & $0,05 \mathrm{a}$ & $23,90 \mathrm{c}$ \\
T 1 & $20,22 \mathrm{c}$ & $0,62 \mathrm{~b}$ & $7,87 \mathrm{a}$ & $0,35 \mathrm{a}$ & $70,93 \mathrm{ab}$ \\
T 2 & $31,27 \mathrm{~b}$ & $0,46 \mathrm{~b}$ & $2,39 \mathrm{~d}$ & $0,27 \mathrm{a}$ & $65,60 \mathrm{~b}$ \\
T 3 & $11,63 \mathrm{c}$ & $0,33 \mathrm{~b}$ & $6,05 \mathrm{ab}$ & $0,40 \mathrm{a}$ & $81,60 \mathrm{a}$ \\
T 4 & $20,64 \mathrm{c}$ & $0,67 \mathrm{~b}$ & $5,41 \mathrm{bc}$ & $0,25 \mathrm{a}$ & $73,00 \mathrm{ab}$ \\
CV (\%) & 11,69 & 18,39 & 13,85 & 55,36 & 4,79 \\
\hline
\end{tabular}

Nota: Médias seguidas da mesma letra na coluna não diferem entre si pelo teste de Tukey $(p=0,05)$.

A secagem dos estruturados promoveu uma redução no teor de umidade da polpa congelada de cajá-manga $(71,62 \%)$ para todos os tratamentos adotados, sendo que os tratamentos 1 (alginato, gelatina e pectina), 3 (gelatina e pectina) e 4 (alginato e gelatina) não diferiram e apresentaram os menores teores de umidade. $O$ tratamento 2 sem gelatina, foi o que mostrou maior teor de umidade entre as formulações testadas. A Figura 2 mostra que o T2 foi o tratamento que produziu o estruturado com maior pegajosidade ao toque e menor resistência ao corte. $\mathrm{O}$ tratamento 3 , com menor valor de umidade $(11,63 \%)$, está sujeito a uma menor sinérese e consequente maior estabilidade microbiológica do que os outros tratamentos.

CARVALHO et al. (2015), investigando os parâmetros para a estruturação de polpa de umbu, observaram que o processo de secagem dos estruturados promoveu uma redução no teor de umidade para níveis de umidade intermediária variando de $33,55 \%$ a $34,93 \%$. Além disso, a secagem minimizou o problema de adesividade na superfície dos estruturados, proporcionando maior estabilidade e melhoria da textura do produto final. Resultados semelhantes foram obtidos por OLIVEIRA et al. (2010), estudando a elaboração e caracterização de estruturado obtido de polpa concentrada de cupuaçu, estes autores relataram teores de umidade variando entre $25,33 \%$ e $26,50 \%$, para as diferentes formulações estudadas.

Com relação aos teores de lipídios e cinzas, não houve diferença estatística entre os tratamentos/estruturados. O teor de cinzas na polpa de cajá-manga $(1,06 \%)$ foi estatisticamente superior aos encontrados nas quatro formulações testadas. Os valores de lipídios encontrados nas análises foram baixos, variando de $0,25 \%$ e $0,40 \%$. Valores semelhantes foram encontrados por CARVALHO et al. (2015), estudando estruturados de umbu, em que os valores de lipídios variaram entre $0,29 \%$ e $0,31 \%$, podendo ser considerados novos produtos de baixo teor de gordura, fato que é importante para os consumidores ao adquirirem produtos saudáveis.

Para o teor de proteína, verificou-se valores variando entre $2,39 \%$ e $7,87 \%$, para as quatro formulações de estruturado estudadas. A principal contribuição para aumento do teor proteico foi a utilização da gelatina, o que pode ser comprovado no tratamento 2 (alginato e pectina) no qual não houve adição de gelatina, que resultou em um valor proteico de $2,39 \%$. O teor proteico do tratamento 2 (alginato e pectina) e da polpa de cajá-manga (3,42\%) não diferiram entre si. O tratamento 1 (alginato, gelatina e pectina) apresentou maior valor proteico $(7,87 \%)$, mas não diferiu do tratamento 3 (gelatina e pectina), que apresentou média de 6,05\%. Com a adição dos hidrocoloides, elevou-se em até $43 \%$ o teor de proteína da polpa de cajá-manga, obtendo-se assim, um produto com maior teor de proteína.

Para o teor de carboidratos, o tratamento 3 (gelatina e pectina) apresentou maior média $(81,60 \%)$, mas não houve diferença do tratamento 1 (alginato, gelatina 
e pectina) e do tratamento 4 (alginato e gelatina). $O$ tratamento 2 (T2), sem a adição de gelatina, apresentou numericamente o menor teor de carboidratos $(65,6 \%)$ entre as quatro formulações testadas, mas não diferiu significativamente dos tratamentos 1 e 4 (T1 e T4).

O tratamento 2 (pectina e alginato) apresentou maior teor de umidade e menores teores de proteínas, carboidratos, $\mathrm{pH}$, sólidos solúveis e valor calórico total quando comparado com as demais formulações testadas. O menor teor de proteína nesse tratamento (T2) pode ser explicado pela ausência de gelatina nessa formulação (Tabela 1) e o maior teor de umidade encontrado para o tratamento 2 $(31,27 \%)$ pode justificar a observação visual de menor firmeza do estruturado de polpa de cajá-manga obtido como mostrado na Figura 2.

TABELA 4: Análises físico-químicas para cada formulação do gel de fruta e a polpa de cajá-manga.

\begin{tabular}{cccc}
\hline Formulações & $\mathrm{pH}$ & Sólidos Solúveis ('Brix) & VET (kcal/100g) \\
Polpa & $2,80 \mathrm{~d}$ & $13,75 \mathrm{c}$ & $109,53 \mathrm{~d}$ \\
T 1 & $4,56 \mathrm{a}$ & $69,66 \mathrm{ab}$ & $318,38 \mathrm{ab}$ \\
T 2 & $3,66 \mathrm{c}$ & $65,00 \mathrm{~b}$ & $274,42 \mathrm{c}$ \\
T 3 & $3,7 \mathrm{bc}$ & $70,66 \mathrm{ab}$ & $354,12 \mathrm{a}$ \\
T 4 & $3,96 \mathrm{~b}$ & $73,66 \mathrm{a}$ & $315,97 \mathrm{~b}$ \\
CV $(\%)$ & 2,23 & 3,58 & 3,73 \\
\hline
\end{tabular}

Nota: Médias seguidas da mesma letra na coluna não diferem entre si pelo teste de Tukey $(p=0,05)$.

Conforme pode ser observado na Tabela 4, a adição de sacarose, na elaboração do estruturado, elevou o teor de sólidos solúveis, comparado com o da polpa de cajá-manga $\left(13,75^{\circ}\right.$ Brix). O tratamento 4 (alginato e gelatina) apresentou maior valor para o teor de sólidos solúveis $\left(73,66^{\circ} \mathrm{Brix}\right)$, mas não diferiu dos tratamentos T1 (alginato, gelatina e pectina) e T3 (gelatina e pectina). O T2 (alginato e pectina), que não apresentava gelatina na formulação apresentou teor de sólidos solúveis significativamente menor (65\%) que a formulação 4 e estatisticamente igual ao das formulações 3 e 1 (T3 e T1). Com relação ao pH, o maior valor foi encontrado na formulação 1 (T1), 4,56 e as formulações 3 e 4, com valores de 3,7 e 3,96, respectivamente, não diferiram entre si. Da mesma maneira as formulações 2 e 3 , não diferiram.

Para o valor energético total, o tratamento 3 (gelatina e pectina) apresentou maior média $(354,12 \mathrm{kcal} / 100 \mathrm{~g})$, que não diferiu do tratamento 1 (alginato, gelatina e pectina), o qual também não diferiu do tratamento 4 (alginato e gelatina). $O$ tratamento 2 (alginato e pectina) apresentou menor média para o valor energético total $(274,42 \mathrm{kcal} / 100 \mathrm{~g})$ sendo superior apenas ao valor da polpa $(109,53 \mathrm{kcal} / 100$ g). Damiani et al. (2011), encontrou para a polpa de cajá-manga um valor de 64,10 $\mathrm{kcal} / 100 \mathrm{~g}$, valor inferior ao encontrado no trabalho, entretanto tal parâmetro não está disponível na TACO (2011).

Mesmo que o produto elaborado seja nutricionalmente adequado, são ainda necessárias análises microbiológicas e sensoriais, para avaliar tanto o tempo de prateleira do produto elaborado (shelf-life) e a segurança microbiológica durante o armazenamento quanto a percepção dos consumidores aos atributos sensoriais do estruturado para que o mesmo não seja rejeitado.

\section{CONCLUSÕES}


A metodologia mostrou-se viável para a produção do gel de fruta a partir da polpa de cajá-manga. Verificou-se que a associação da pectina e da gelatina permitiu a obtenção de um produto com maior valor nutricional e que apresentou melhor aspecto visual. A ausência da gelatina proporcionou um produto com menor teor nos parâmetros nutricionais avaliados e a metodologia de secagem adotada no trabalho permitiu a elaboração do estruturado com redução significativa no teor de umidade da polpa de cajá-manga. Análises sensoriais e microbiológicas devem ser realizadas para complementar os resultados e determinar não apenas a formulação mais adequada nutricionalmente, mas também a segurança microbiológica e a percepção sensorial dos consumidores ao produto elaborado.

\section{REFERÊNCIAS}

BRASIL. Ministério da Saúde. Agência Nacional de Vigilância Sanitária - Anvisa. Resolução RDC $n^{\circ}$ 360, de 23 de dezembro de 2003. Regulamento Técnico sobre Rotulagem Nutricional de Alimentos Embalados. Diário Oficial da União, Brasília, DF, 26 dez. 2003.

BUSANELLO, M. P. Desenvolvimento de bebida láctea prebiótica com cajámanga (Spondias dulcis). 2014. 51f. Trabalho de Conclusão de Curso (Graduação em Tecnólogo de Alimentos) - Universidade Federal do Paraná, Francisco Beltrão, $2014 . \quad$ Disponível em: <http://repositorio.roca.utfpr.edu.br/jspui/bitstream/1/3462/1/FB_COALM_2014_2_08. pdf $>$

CARVALHO, A. V.; NOGUEIRA, J. G.; MATTIETTO, R. A. Elaboração e caracterização de estruturados de umbu. Embrapa - Boletim de Pesquisa e Desenvolvimento, Belém, 2015. Disponível em: $<$ http://biblioteca.universia.net/html_bura/ficha/params/title/elabora \%C3\%A7\%C3\%A3o-caracteriza\% $\overline{\mathrm{C}} 3 \% \mathrm{~A} 7 \% \mathrm{C} 3 \% \mathrm{~A} 30$-estruturadosumbu/id/62207776.html>

DAMIANI, C.; SILVA, F. A.; AMORIM, C. C. M.; SILVA, S. T. P.; BASTOS, I. M.; ASQUIEIRI, E. R.; VERA, R. Néctar misto de cajá-manga com hortelã: caracterização química, microbiológica e sensorial. Revista Brasileira de Produtos Agroindustriais, Campina Grande, v.13, n.3, p.301-309, 2011. Disponível em: <http://www.deag.ufcg.edu.br/rbpa/rev133/Art1330.pdf>

GRIZOTTO, R. K.; AGUIRRE, J. M.; MENEZES, H. C. Frutas estruturadas de umidade intermediária obtidas de polpas concentradas de abacaxi, manga e mamão. Ciência e Tecnologia de Alimentos, Campinas, v. 25, n. 4, p. 691-697, 2005. Disponível em: < http://dx.doi.org/10.1590/S0101-20612005000400011>. doi: 10.1590/S0101-20612005000400011

LAGO-VANZELA, E. S.; RAMIN, P.; UMSZA-GUEZ, M. A.; SANTOS, G. V.; GOMES, E.; SILVA, R. Chemical and sensory characteristics of pulp and peel 'cajá-manga' (Spondias cytherea Sonn.) jelly. Ciência e Tecnologia de Alimentos, Campinas, v. 31, n. 2, p. 398-405, 2011. Disponível em: <http://dx.doi.org/10.1590/S010120612011000200018> . doi: 10.1590/S0101-20612011000200018 
MORZELLE, M. C.; BACHIEGA, P.; SOUZA, E. C.; BOAS, E. V. B. V.; LAMOUNIER, M. L. Caracterização química e física de frutos de curriola, gabiroba e murici provenientes do cerrado brasileiro. Revista Brasileira de Fruticultura, Jaboticabal SP, v. 37, n. 1, p. 096-103, 2015. Disponível em: <http://dx.doi.org/10.1590/01002945-036/14> . doi: 10.1590/0100-2945-036/14

OLIVEIRA, J. A. R.; CARVALHO, A. V.; MOREIRA, D. K. T.; MARTINS, L. H. D. S. Elaboração e caracterização de estruturado obtido de polpa concentrada de cupuaçu. Revista de Ciências Agrárias, Belém, v. 53, n. 2, p. 164-170, 2010. Disponível em: <https://www.embrapa.br/busca-depublicacoes/-/publicacao/900530/elaboracao-e-caracterizacao-de-estruturado-obtidode-polpa-concentrada-de-cupuacu>. doi: 10.4322/rca.2011.023

OLIVEIRA, J. A. R.; CARVALHO, A. V.; MARTINS, L. H. S.; MOREIRA, D. K. T. Elaboração e caracterização físico-química e sensorial de estruturados de polpa concentrada de abacaxi. Alimentos e Nutrição, Araraquara v. 23, n. 1, p. 23-31, 2012. Disponível em: <http://servbib.fcfar.unesp.br/seer/index.php/alimentos/article/viewFile/1440/1201>.

RUFINO, M. S. M.; BRITO, E. S.; JIMÉNEZ, J. P.; CALIXTO, F. S.; MANCINI FILHO, $J$. Bioactive compounds and antioxidant capacities of 18 non-traditional tropical fruits from Brazil. Food chemistry, v. 121, n. 4, p. 996-1002, 2010. Disponível em: < http://dx.doi.org/10.1016/j.foodchem.2010.01.037 >. doi: 10.1016/j.foodchem.2010.01.037

SILVA, G. A.; BRITO, N. J. N.; SANTOS, E. C. G.; LÓPEZ, J. A.; ALMEIDA, M. G. Gênero Spondias: Aspectos botânicos, composição química e potencial farmacológico. BioFar, v. 10, n. 01, 2014. Disponível em: <http://sites.uepb.edu.br/biofar/download/v10n1-2014/G\%C3\%8ANERO $\% 20$ Spondias $\% 20$ ASPECTOS\%20BOT\%C3\%82NICOS\%20COMPOSI \%C3\%87\%C3\%830\%20QU\%C3\%8DMICA\%20E\%20POTENCIAL\%20FARMACOL $\%$ C3\%93GICO.pdf>

SIQUEIRA, A. P. S.; VASCONCELOS, L. H. C.; VENDRUSCOLO, E. P.; CUSTÓDIO, B. S. S.; COSTA, D. P.; FARIA, T. C.; SELEGUINI, A. Climatization for scheduled ripening of caja-manga. African Journal of Agricultural Research, v. 12, p. 424-428, 2017. Disponível em: <http://www.academicjournals.org/AJAR>. doi: 10.5897/AJAR2016.11565

TACO -TABELA BRASILEIRA DE COMPOSIÇÃO DE ALIMENTOS. Universidade Estadual de Campinas - UNICAMP. $4^{\mathrm{a}}$ ed, 161 p, 2011. 